\title{
Heavy duty diesel exhaust particles during engine motoring formed by lube oil consumption
}

\section{Supplemental Information}

Panu Karjalainen ${ }^{1}$, Leonidas Ntziachristos ${ }^{1,{ }^{*}}$, Timo Murtonen ${ }^{2}$, Hugo Wihersaari ${ }^{1}$,

Pauli Simonen ${ }^{1}$, Fanni Mylläri ${ }^{1}$, Nils-Olof Nylund ${ }^{2}$, Jorma Keskinen ${ }^{1}$, Topi Rönkkö ${ }^{1}$

${ }^{1}$ Aerosol Physics Laboratory, Department of Physics, Tampere University of Technology, P.O. Box 692, 33101 Tampere, Finland

${ }^{2}$ VTT Technical Research Centre of Finland Ltd., P.O. Box 1000, 02044 VTT, Espoo, Finland

* Corresponding author, email: leonidas.ntziachristos@tut.fi

Number of pages: 7, Number of Figures: 7, Number of Tables : 1

Vehicle Specifications

Table S1. Test vehicle characteristics and emissions levels, following Regulation (EU) 582/2011, over the WHVC test cycle.

\begin{tabular}{|c|c|c|c|}
\hline & Vehicle & Truck & Bus \\
\hline \multirow{11}{*}{ 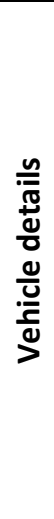 } & Registration year & 2007 & 2005 \\
\hline & Emission stage & Euro IV & Euro III \\
\hline & Engine Displacement (I) & 8.9 & 9.0 \\
\hline & Emissions control & $\mathrm{EGR}+\mathrm{DOC}$ & EGR \\
\hline & Crankcase venting & $\begin{array}{l}\text { Open crankcase } \\
\text { ventilation (OVC) }\end{array}$ & $\begin{array}{l}\text { Open crankcase } \\
\text { ventilation (OVC) }\end{array}$ \\
\hline & Mass - GVWR ${ }^{(1)}(\mathrm{t})$ & 18 & 18 \\
\hline & Transmission & Manual & Automatic \\
\hline & Odometer $\left(\times 10^{3} \mathrm{~km}\right)$ & 879 & 997 \\
\hline & Fuel consumption kg/100 km & 22.0 & 25.5 \\
\hline & Simulated chassis inertia (kg) & 13805 & 14950 \\
\hline & Curb weight (kg) & 9700 & 11900 \\
\hline \multirow{6}{*}{ 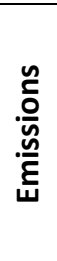 } & $\mathrm{CO}(\mathrm{g} / \mathrm{km})$ & 1.3 & 0.9 \\
\hline & $\mathrm{HC}(\mathrm{g} / \mathrm{km})$ & 0.1 & 0.2 \\
\hline & $\mathrm{NO}_{\mathrm{x}}(\mathrm{g} / \mathrm{km})$ & 4.0 & 4.8 \\
\hline & $\mathrm{CO}_{2}(\mathrm{~g} / \mathrm{km})$ & 717 & 815 \\
\hline & $\mathrm{PM}(\mathrm{g} / \mathrm{km})$ & 0.07 & 0.13 \\
\hline & $\mathrm{PN}_{>23 \mathrm{~nm}}(1 / \mathrm{km})$ & $7.0 \times 10^{13}$ & $13 \times 10^{13}$ \\
\hline
\end{tabular}

(1) Gross Vehicle Weight Rating as specified by the manufacturer 


\section{Exhaust sampling and instrumentation}

Two types of exhaust sampling systems were used in the study. First, partial exhaust sampling consisting of a porous tube diluter, a residence time chamber and ejector type diluter ${ }^{1}$ was used in order to mimic real atmospheric dilution process of exhaust ${ }^{2,3}$ and thus to get information e.g. on the semivolatile exhaust particle components. This system was installed as close as possible to the tailpipe outlet to minimize the residence time of exhaust from engine to sampling location. The system was used with primary dilution ratio of 12:1, dilution air temperature of $30^{\circ} \mathrm{C}$, and with secondary dilution ratio of $8: 1$, obtained with an ejector dilutor. After the secondary dilution the diluted exhaust sample was delivered to aerosol instruments, whether directly or through a thermodenuder. The thermodenuder $\left(T=265^{\circ} \mathrm{C}\right)$ was used during some of the cycles to remove the semivolatile compounds from the particles. Because the thermodenuder can induce some losses for non-volatile particles, all results presented in the paper have been corrected for the losses profile presented by Heikkilä et al. ${ }^{4}$ The losses considered were $32 \%$ and $50 \%$ for mobility sizes 10 and $4.5 \mathrm{~nm}$, respectively.

Particle size distributions of the diluted exhaust sample were measured by an Engine Exhaust Particle Sizer (EEPS, TSI Inc. $)^{5}$, a High-Resolution Low-Pressure Impactor (HR-LPI) ${ }^{6}$ and with an ELPI+ (Dekati Inc.) instrument. Particle size distribution data presented in this paper are only from EEPS measurements, using the default inversion matrix of the instrument. The particle number concentration was measured using three Condensation Particle Counters (CPCs), each exhibiting a different lower cut size: CPC 3776 (TSI Inc.) with cut off size $2.5 \mathrm{~nm}$, CPC A20 (Airmodus Inc.) with cut off size of $7 \mathrm{~nm}$ and CPC 3775 (TSI Inc.) with modified cut off size of $23 \mathrm{~nm}$. Background concentration levels using HEPA-filtered dilution air were at 0 particles $/ \mathrm{cm}^{3}$, hence no correction to measured levels was necessary.

In order to study particle morphology and elemental composition, the exhaust particles were collected from the diluted sample on holey-carbon grids (Agar Scientific) by a flow-through sampler where flow of $1 \mathrm{l} / \mathrm{min}$ was used. In the sampler, the flow was forced through porous holey-carbon grids so that particles were collected by diffusion, inertial impaction, and interception on the substrate. The loaded grids with individual particles were then analyzed by shape with a transmission electron microscopy (TEM, Jeol JEM-2010) and by elemental composition with an energy dispersive X-ray spectrometry (EDS Noran Vantage with $\mathrm{Si}(\mathrm{Li})$ detector, Thermo Scientific). Mostly qualitative analysis was performed to the TEM and EDS results and no number counting or sizing was performed.

The second sampling system was used for gaseous pollutants and particulate matter sampling and fulfilled the requirements for regulated pollutants emission measurements. The primary dilution was conducted by Constant Volume Sampler (CVS, Pierburg AMA 4000) from which the sample was taken to particle number measurement, consisting of two diluters and an evaporation tube (Dekati Inc., DEED) and CPC with cut off size of $23 \mathrm{~nm}$ (Airmodus Inc., A23). These results ( $\mathrm{PN}>23 \mathrm{~nm}$ ) as well as results for other regulated pollutants ( $\mathrm{CO}, \mathrm{HC}, \mathrm{NO}_{x}, \mathrm{PM}$ ) over the WHVC cycle are shown in Table S1. Photos of the vehicle testing and sampling setup are shown in Figure $\mathrm{S} 1$. 


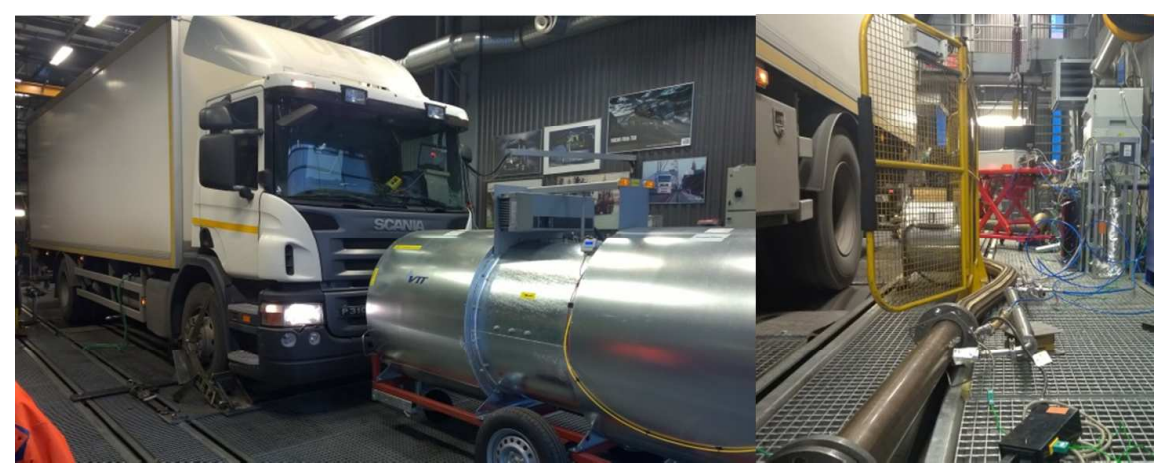

Figure S1. Photo from the experiments for the truck: (left) overall layout and (right) sampling system and devices.

The lubricant oil was also analyzed for a number of properties. The oil sample was taken from the engine's oil pan and sent for the analysis to a subcontractor. The sample was analyzed for viscosity (ASTM D445), total base number (ISO 3771), additives (ASTM D5185), wear metals (ASTM D5185) and water content (ASTM D6304 C). Also contaminants (silicon, potassium and sodium) were analyzed using ICP.

\section{Detailed testing Results}

Figures S2 to S7 demonstrate time series of all recordings over speed ramp and WHVC tests. In each panel, the upper graphs shows engine load percentage and vehicle speed, the middle graph shows individual CPC recordings and lower graphs shows EEPS size distribution spectra. All measurements have been synchronized to the reference signals considered to be obtained at the OBD port. Particle concentration measurements have then be shifted to align peak in number concentrations with the corresponding engine accelerations.
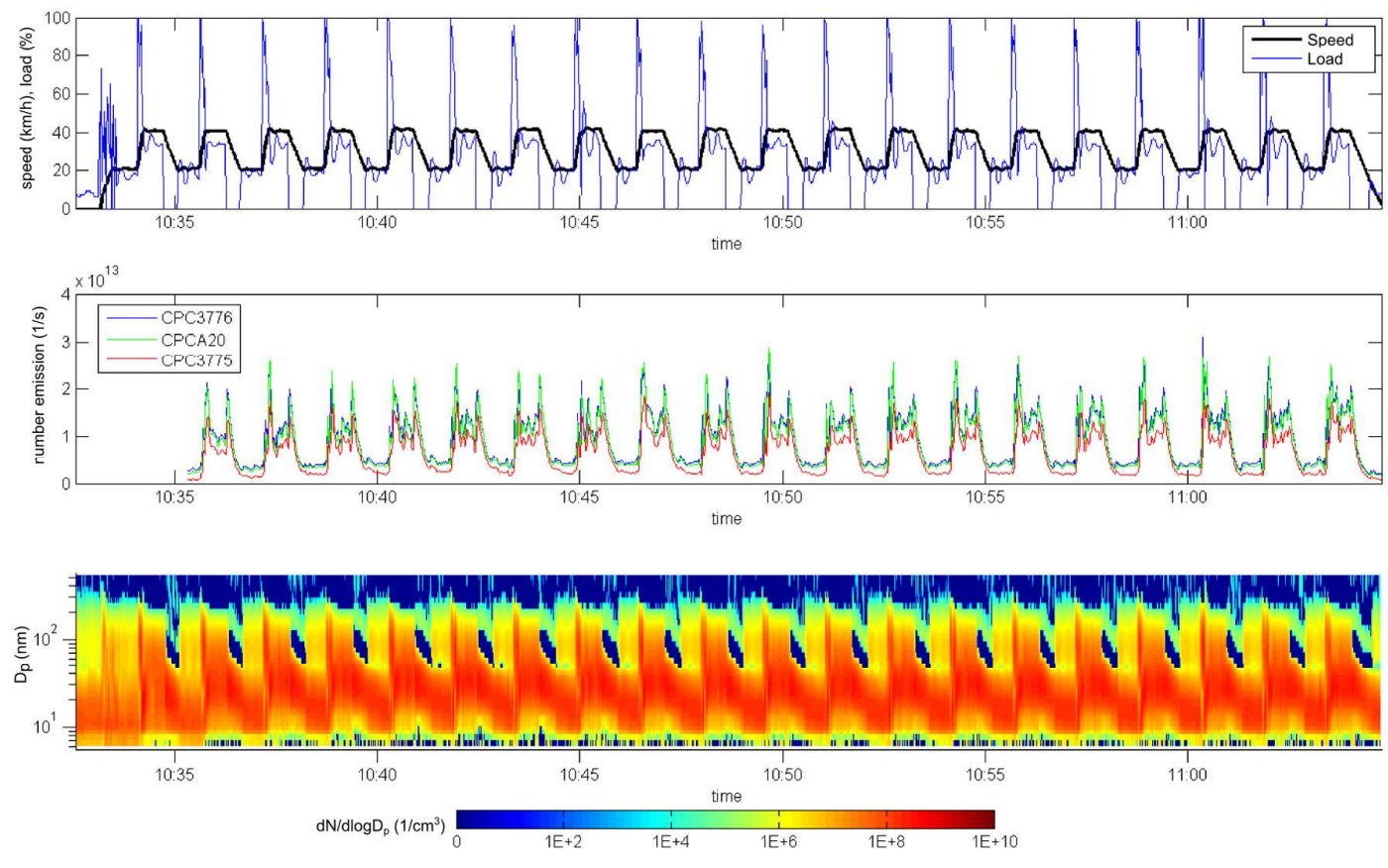

Figure S2. Particle emissions (w/o TD) for the truck during the $40-20 \mathrm{~km} / \mathrm{h}$ speed ramp cycle. Vehicle speed $(\mathrm{km} / \mathrm{h}$ ) and engine load (\%) in the top panel, number emissions (CPCs, 1/s) in the middle panel and particle size distributions measured by the EEPS in the bottom panel. 

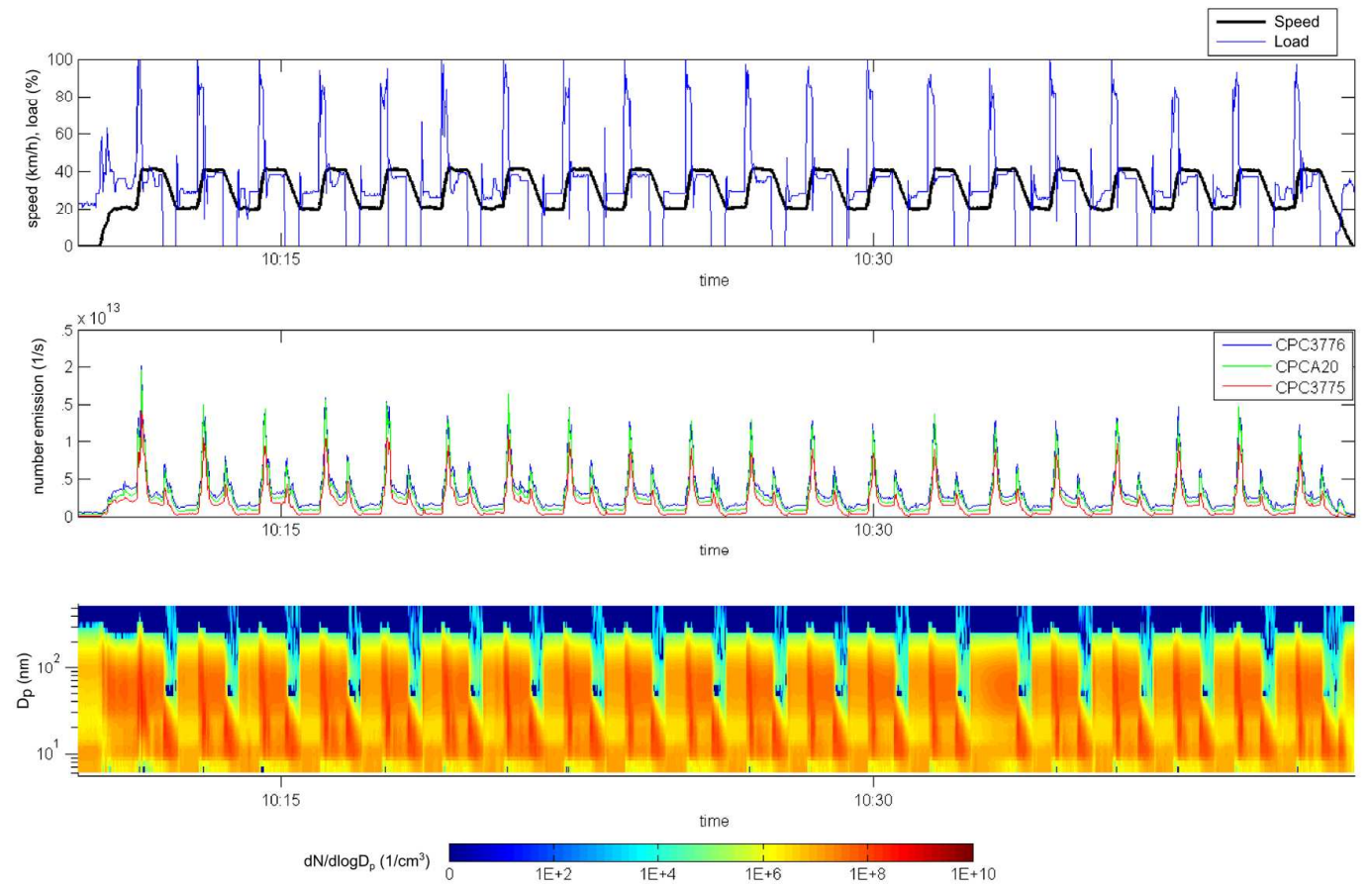

Figure S3. Particle emissions (w/o TD) for the bus during the $40-20 \mathrm{~km} / \mathrm{h}$ speed ramp cycle. Vehicle speed $(\mathrm{km} / \mathrm{h})$ and engine load (\%) in the top panel, number emissions (CPCs, 1/s) in the middle panel and particle size distributions measured by the EEPS in the bottom panel. 

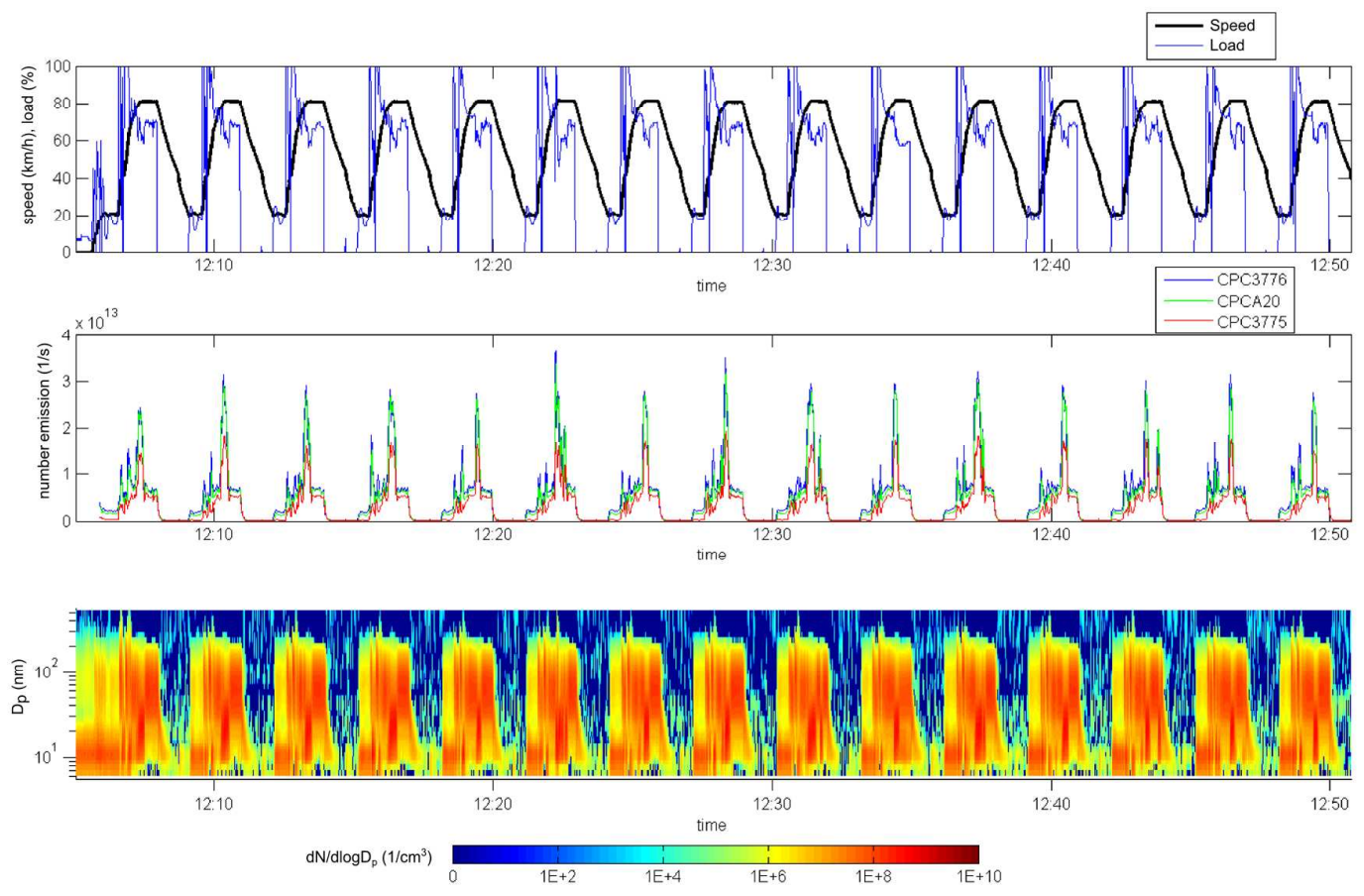

Figure S4. Particle emissions (w/o TD) for the truck during the $80-20 \mathrm{~km} / \mathrm{h}$ speed ramp cycle. Vehicle speed $(\mathrm{km} / \mathrm{h})$ and engine load (\%) in the top panel, number emissions (CPCs, 1/s) in the middle panel and particle size distributions measured by the EEPS in the bottom panel.
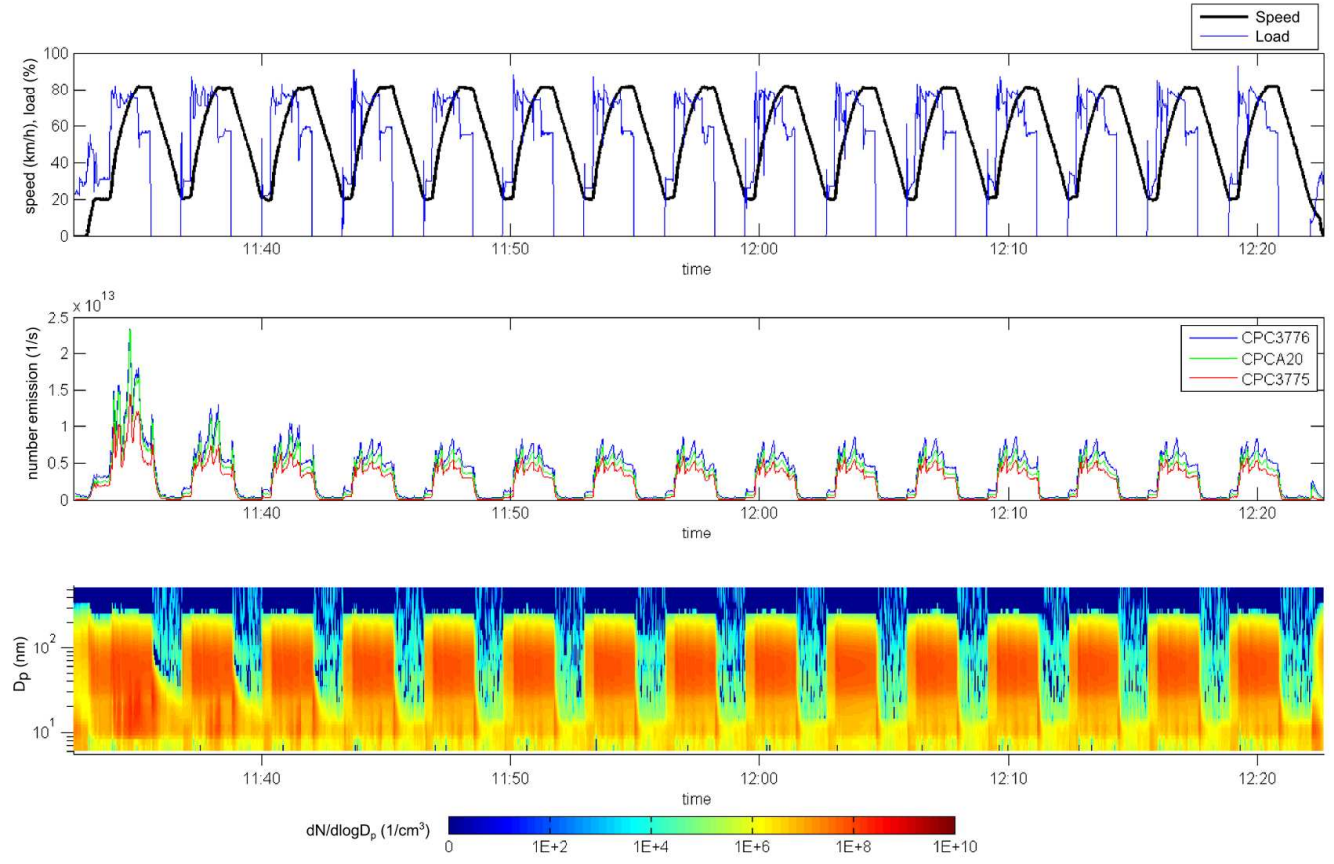

Figure S5. Particle emissions (w/o TD) for the bus during the $80-20 \mathrm{~km} / \mathrm{h}$ speed ramp cycle. Vehicle speed $(\mathrm{km} / \mathrm{h})$ and engine load (\%) in the top panel, number emissions (CPCs, 1/s) in the middle panel and particle size distributions measured by the EEPS in the bottom panel. 

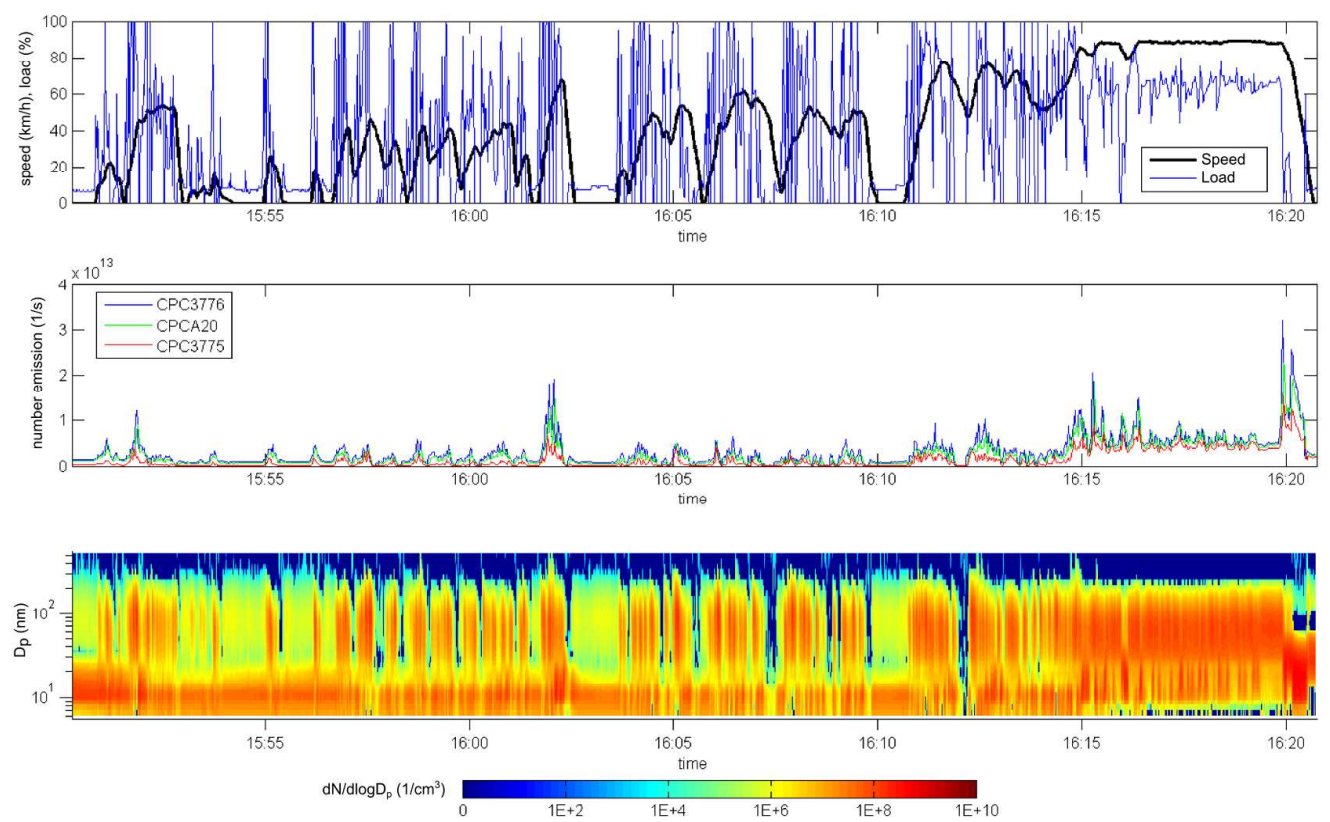

Figure S6. Particle emissions (w/o TD) for the truck during the WHVC cycle. Vehicle speed $(\mathrm{km} / \mathrm{h})$ and engine load (\%) in the top panel, number emissions (CPCs, 1/s) in the middle panel and particle size distributions measured by the EEPS in the bottom panel.
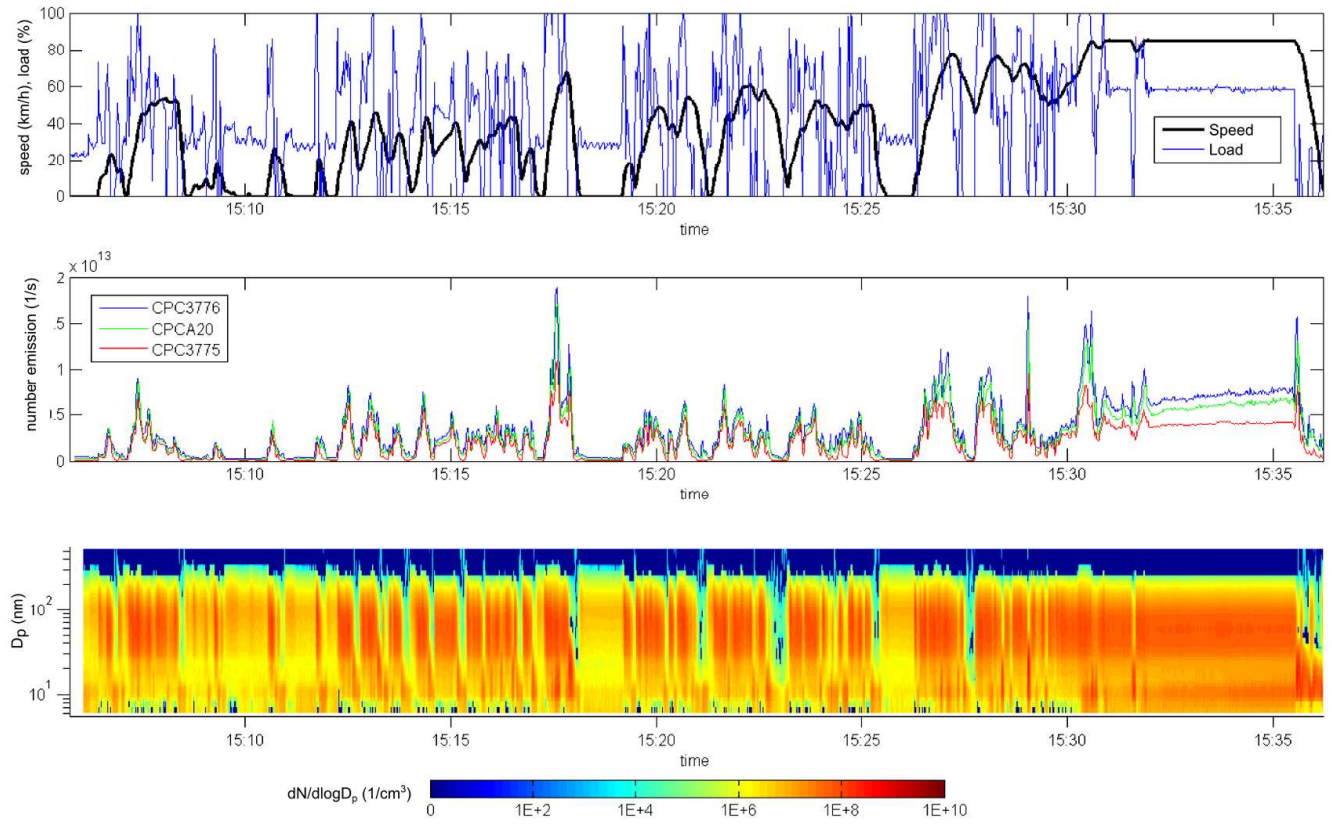

Figure S7. Particle emissions (w/o TD) for the bus during the WHVC cycle. Vehicle speed $(\mathrm{km} / \mathrm{h}$ ) and engine load (\%) in the top panel, number emissions (CPCs, 1/s) in the middle panel and particle size distributions measured by the EEPS in the bottom panel. 


\section{Supplemental Information References}

1. Ntziachristos, L.; Samaras, Z., The Potential of a Partial-Flow Constant Dilution Ratio Sampling System as a Candidate for Vehicle Exhaust Aerosol Measurements Leonidas Ntziachristos. J. Air Waste Manage. 2010, 60 (10), 1223-1236; DOI 10.3155/1047-3289.60.10.1223.

2. Giechaskiel, B.; Ntziachristos, L.; Samaras, Z.; Scheer, V.; Casati, R.; Vogt, R., Formation potential of vehicle exhaust nucleation mode particles on-road and in the laboratory. Atmos. Environ. 2005, 39 (18), 3191-3198; DOI 10.1016/j.atmosenv.2005.02.019.

3. Rönkkö, T.; Virtanen, A.; Vaaraslahti, K.; Keskinen, J.; Pirjola, L.; Lappi, M., Effect of dilution conditions and driving parameters on nucleation mode particles in diesel exhaust: Laboratory and on-road study. Atmos. Environ. 2006, 40 (16), 2893-2901; DOI 10.1016/j.atmosenv.2006.01.002.

4. Heikkilä, J.; Rönkkö, T.; Lähde, T.; Lemmetty, M.; Arffman, A.; Virtanen, A.; Keskinen, J.; Pirjola, L.; Rothe, D., Effect of Open Channel Filter on Particle Emissions of Modern Diesel Engine. J. Air Waste Manage. 2009, 59 (10), 1148-1154; DOI 10.3155/1047-3289.59.10.1148.

5. Johnson, T.; Caldow, R.; Pöcher, A.; Mirme, A.; Kittelson, D., A new electrical mobility particle sizer spectrometer for engine exhaust particle measurements. SAE Paper 2004, 2004-011341; DOI 10.4271/2004-01-1341.

6. Arffman, A.; Yli-Ojanperä, J.; Kalliokoski, J.; Harra, J.; Pirjola, L.; Karjalainen, P.; Rönkkö, T.; Keskinen, J., High-resolution low-pressure cascade impactor. J. Aerosol Sci. 2014, 78, 97-109; DOI 10.1016/j.jaerosci.2014.08.006. 